and cantilevers. Economically, prestressing means a saving in materials; this can be set against the extra cost incurred in factory or site production. Emphasis is rightly laid on the paramount necessity of the fullest co-operation between architect, engineer and contractor if full advantage is to be taken of prestressed concrete in buildings.

The advent of the MI motorway, perhaps more than any other highway development in Britain since the end of the Second World War, impressed on the general public the fact that the art of concrete bridge design had not only come to stay but was potentially capable of rapidly increasing development in modern eivil engineering projects. In point of fact, concrete, and particularly prestressed concrete, has since become the almost universally favoured constructional material for bridges in Britain, as in the United States, Europe and elsewhere. From 1950 onwards, many highway bridges were constructed in prestressed concrete, but almost every design depended on the particular local problem with which the engineer was at the time concerned. Consequently, a large variety of prestressed beam sections was devised, each requiring a special formwork, much of this without any attempt at standardization.

Manufacturers found that when some form of standardization was tried for their beam section products, as proprietary units, dependence on such beams in certain cirumstances conflicted with the requirements of local authorities and the Ministry of Transport when it aame to competitive tendering for contracts. The economic and practical advantages stemming from some form of standardization of precast concrete beam sections for bridges for specific open ranges, acceptable alike to the Ministry, local authorities and products manufacturers, soon became the terms of reference of the Prestressed Concrete Development Group which pioneered the publication Standard Beam Sections for Prestressed Concrete Bridges: (1) Inverted T Beams for Spans from 25 to $55 \mathrm{ft}$. (Second edition. London: Cement and Concrete Association, October 1963).

In the range of apans from 40 to $85 \mathrm{ft}$., the most frequently used sections are either hollow box or composite $T$ sections, and in this connexion a further booklet, $P c .4$, Standard Beam Sections for Prestressed Concrete Bridges: (2) Box Section Beams for Spans from 40 to $85 \mathrm{ft}$. has been published by the Group $\dagger$. Concerning these particular spans, ". . experience has shown that an economical solution can be provided either by a bridge deck com. prising beams of hollow box section placed side by side with narrow in situ joints between, or by one in which beams of precast I section, more widely spaced, are made composite with an in situ slab on top, and thus act as T beams". This booklet (Pc. 4) gives details of recommended box section units; it also includes examples of typical analyses of bridges using the standard sections.

It is intended that the I sections for composite T-beam bridges will be described in a later booklet. It is also predicted that standard sections may be extended in future to spans exceeding $85 \mathrm{ft}$.; such sections, however, would probably have to be post-tensioned owing to the Ministry's present edict prohibiting transport by road of loads more than $90 \mathrm{ft}$. long.

† Prestressed Concrete Development Group. Slandard Beam Sections for Prestressed Bridges-(2) Box Section Beams for Spans from 40 to $85 \mathrm{ft}$. Pp. 16. (London: Prestressed Concrete Development Group, 1964.)

\title{
THE LABORATORY ANIMAL SCIENCE ASSOCIATION
}

$\mathrm{R}$ ECENT developments in such widely differing spheres as chemotherapy, nutrition, toxicology and virology have led to changes in the role of experimental animals in research. A more general awareness is developing in the basic biological disciplines that projects involving experimental animals are more likely to be brought to a successful conclusion if the animals themselves are healthy and are accorded proper care. The production of healthy animals has in itself led to a new field of research, utilizing techniques to control their bacterial flora and eliminate unwanted parasites. The cost of animals and providing for their maintenance during experimentation is far from negligible, and efficiency both of production and usage is a goal to be attained.

Those whose scientific interest is in this sphere are from a variety of disciplines, and it is to be regretted that at this time there is no formal training in the scientific aspects of laboratory animal care available in the United Kingdom.

For the past seventeen years, the Laboratory Animals Centre (formerly Bureau) of the Medical Research Council has acted as an agency for the dissemination of information and advice on laboratory animals, a task which it has performed with notable success. The present director of the Centre, Dr. Lane-Petter, has been responsible for the organization of an annual symposium dealing with some broad aspects of laboratory animal science. The large attendances at these meetings were, in themselves, evidence of the keen interest shown by research workers to improve their knowledge of the proper care and use of laboratory animals.

The success of these meetings prompted scientists in both academic and industrial institutions to hold discussions with representatives of the Laboratory Animals Centre, the Universities Federation for Animal Welfare and the Animal Technicians Association concerning the formation of an essentially graduate organization interested in all aspects of laboratory animal science.
These discussions led to the formation of the Laboratory Animal Science Association in November 1963. Among the objectives of the new Association are the exchange of information between scientists and others concerned with the production, use and care of experimental animals and the stimulation of educational bodies, particularly the universities, to provide undergraduate and postgraduate training in laboratory animal science. It also seeks to co-operate with other organizations interested in the promotion of the highest standard of animal care through. out Britain.

It is intended to hold symposia and lectures and to arrange meetings for the presentation and discussion of papers by members. It is also hoped to organize visits to laboratories and breeding units for demonstrations of equipment and techniques.

Dr. Lane-Petter has made available the annual Laboratory Animals Centre Symposium and the associated Collected Papers as the basis for future meetings and publications. The first symposium of the new Association will be held on May 20 at the Royal Society of Medicine, 1 Wimpole Street, London, W.1. The topies to be discussed include: the significance of organ weights in toxicity testing (Dr. L. Golberg); factors affecting the growth rate of laboratory animals (Dr. E. Widdowson); and the use of laboratory animals in experimental hrema. tology (Dr. E. V. Hulse).

The first publication of the Association (Laboratory Animal Science) will include papers selected from those presented to the NATO Advanced Study Institute on Experimental Animals in Research held at Harrogate during September 9-20, 1963 (Nature, 201, 354; 1964).

Further information concerning the Laboratory Animal Science Association can be obtained from the honorary secretary, Dr. D. E. Stevenson, Tunstall Laboratory, 'Shell' Research, Ltd., Sittingbourne, Kent. 